\title{
Educação escolar: a vez \\ e a voz das crianças
}

Cristine Tinoco da Cunha Lima Rosado* Maria Estela Costa Holanda Campelo"

\section{Resumo}

0 texto tem como finalidade discutir a problemática que assim se configura: Quais as concepções das crianças acerca do seu direito ao ensino fundamental, como etapa obrigatória da educação básica? Que avaliações são feitas pelas crianças sobre a escola de ensino fundamental, em termos de sua finalidade, prática pedagógica e aquisições proporcionadas aos seus usuários, notadamente no que concerne à alfabetização? Visando responder a essas questões, trabalhamos com 20 crianças dos anos iniciais do ensino fundamental de duas escolas, uma estadual e outra municipal, tendo como eixo fundante da pesquisa a fala das crianças acerca do seu contexto escolar. Como resultado inicial, alertamos aos atores da dinâmica escolar a lançarem um olhar mais acurado para o que dizem as crianças e como delineiam o seu lócus principal de aprendizagem.

Palavras-chave: Infância. Direito à educação. Dinâmica escolar.

\section{Elementary education: the time and voice of children Abstract}

The text aims to discuss the following problems: What are the perceptions of children about their right to elementary education as a compulsory step of basic education? What assessments are made by children on the elementary school, in terms of its purpose, pedagogical practice, and acquisitions provided, especially in regard to literacy? In order to answer these questions, we worked with 20 children from the early years of elementary education at two schools, one state and another municipal, with the central focus of the research on the children's perception about

Doutoranda em Educação, Universidade Federal do Rio Grande do Norte (UFRN); Diretora Adjunta do Centro de Educação Integrada, Natal, RN. E-mail: cristine.rosado@ig.com.br

•. Doutorado em Educação, UFRN; Professora Associada da UFRN. E-mail: estelacampelo@hotmail.com 
their school context. As an initial result, we warned the actors of the school dynamics to take a more accurate look to what the children say and how they outline their main locus of learning.

Keywords: Childhood. Right to education. School dynamics.

\section{Educación escolar: la hora y la voz de los niños Resumen}

El texto tiene por objeto discutir la siguiente problemática, asi configurada. ¿Qué concepciones tienene los niños acerca de su derecho a la enseñanza básica, como etapa obligatoria de la educación primaria? ¿Qué evaluaciones realizan los niños sobre la escuela primaria, en términos de su finalidad, práctica pedagógica y adquisiciones proporcionadas a sus usuarios, especialmente en lo que se refiere a la alfabetización? Para responder a esos planteos, trabajamos con 20 niños de los primeros grados de la primaria de dos escuelas, una provincial y otra municipal. Se tuvo como eje fundante de la investigación el habla de los niños sobre su contexto escolar. Como resultado inicial, aconsejamos a los actores de la dinámica escolar a observar, de manera más profunda, lo que dicen los niños y cómo delinean su locus principal de aprendizaje.

Palabras claves: Infancia. Derecho a la educación. Dinámica escolar.

\section{Situando o objeto de investigação}

A escola deveria ser o local apropriado para práticas democráticas, ou seja, um espaço em que todos os sujeitos envolvidos tivessem oportunidade de expressar suas ideias, refletir, defendê-las (FREIRE, 1996; ALARCÃO, 2001; ASSMANN, 2007). No entanto, ainda percebemos que muitas práticas pedagógicas não valorizam, suficientemente, as possiveis contribuições que a escuta dos alunos pode possibilitar o aprimoramento do processo educacional.

A escolha deste tema de estudo relaciona-se, primordialmente, às preocupações para entender concepções de crianças sobre sua escolarização, com a finalidade de aproximar a prática pedagógica dos anseios infantis, tornando-a mais significativa. Assim sendo, pretendemos sistematizar os saberes/dizeres de crianças, no sentido de oferecer contribuições que possam orientar a atuação docente com vistas a intervenções adequadas para melhor aprendizagem dos alunos.

Entendemos que as crianças possuem e constroem saberes, têm visão de mundo que, se explicitadas e mediadas, podem se tornar elementos importantes da investigação científica. Nesse sentido, discutir o saber infantil sobre a escola assume relevância, principalmente na perspectiva teórico-prática, ou seja, se as formulações teóricas aplicarem-se à prática do Ensino Fundamental, possivelmente tornarão os alunos partícipes efetivos do processo. 
Desenvolve-se rapidamente a pesquisa na área da educação básica escolar. São inúmeros estudos abrangendo diversos temas, em geral, voltados para o cotidiano da prática escolar. Soma-se, ainda, significativa ampliação nos estudos que abordam a construção do conhecimento, na perspectiva de autores como Piaget (1980) e Vygotsky (2004) que referenciam nossa investigação.

Neste trabalho, que se constitui num recorte da nossa Dissertação de Mestrado, realizamos a pesquisa, procurando garantir a participação efetiva de crianças dos anos iniciais do Ensino Fundamental. Entendemos que essa participação ainda se apresenta como um desafio para quem pretende ouvir meninos e meninas, na perspectiva de trabalhos, como o nosso, que objetiva compreender como as crianças percebem a escola no tocante: à estrutura e funcionamento, às relações com o conhecimento, com as outras crianças, com os professores e outros adultos envolvidos no processo.

É indiscutível a valorização atribuida às crianças na atualidade (BRASIL, 1991; FORMOSINHO; KISHIMOTO; PINAZZA, 2007). Sabemos que esta é uma fase de vida singular para o desenvolvimento humano. Por outro lado, ainda parece forte a máxima "as crianças devem ser vistas, mas não ouvidas", desconsiderando a sabedoria contida nas vozes infantis. Urge escutá-las para o estabelecimento de um diálogo entre os principais atores do processo educativo e discurso da prática pedagógica, aproximando nossas ações pedagógicas de uma atividade compartilhada (CAMPOS, 2008). Estudos como os de Ariès (1986) apontam para o percurso histórico do reconhecimento da infância e da valorização de suas singularidades.

Refletir sobre a prática educativa vem se tornando um exercício cada vez mais necessário. Reflexão requer diálogo consigo próprio e com os demais envolvidos, além de propiciar a aprendizagem da escuta. 0 problema em questão implica um convite à valorização da fala e do pensamento infantis, como recursos principais na investigação do que é vivenciado pelas crianças.

Aprender com o conhecimento da criança, suas expressões, entendendo-as como possíveis sujeitos da investigação, é um desafio à sensibilidade dos educadores e às rotinas adotadas, exigindo uma disponibilidade para ouvir esses alunos, portadores de linguagens diferenciadas e produtores de cultura. Não pretendemos, porém, polarizar a relação professores-alunos, como se a valorização do que os alunos sabem possa enfraquecer a autonomia didática dos professores. Os direcionamentos poderão ser recriados com os professores, a partir das perspectivas que atendam às singularidades das crianças.

É comum encontrarmos interpretações que consideram ser a educação, nessa fase, apenas uma preparação para o futuro aluno de níveis subsequentes da escolaridade (KRAMER; LEITE, 2003). Ao contrário de tais entendimentos e com base nas contribuições de concepções sociointeracionistas, enfocaremos a criança, segundo seu desenvolvimento e potencialidades, pensando em direcionamentos que a legitimem como elaboradora de saberes. 
A intenção, no presente estudo, é proporcionar às crianças a participação como atores sociais e, para isto, ouvir suas inquietações, suas concepções referentes ao processo ensino/aprendizagem de que participam. Pensamos que este pode ser um caminho que possibilita confrontar o que é dito na teoria e o que é percebido pelos principais envolvidos no processo educativo.

\section{Aspectos metodológicos}

No âmbito das preocupações aqui colocadas, as questões que nortearam a nossa investigação ficaram, assim, configuradas: Quais as concepções das crianças acerca do seu direito ao Ensino Fundamental, como etapa obrigatória da educação básica? Que avaliações são feitas pelas crianças sobre a escola de Ensino Fundamental, em termos de sua estrutura, funcionamento, organização do tempo/espaço, finalidade, prática pedagógica e aquisições proporcionadas aos seus usuários, notadamente no que concerne à alfabetização?

Optamos, na nossa investigação, pela abordagem qualitativa, que possibilita apreender o objeto de estudo nas suas múltiplas dimensões; tem o ambiente natural como fonte direta de coleta dos dados e o pesquisador como seu principal instrumento; sua preocupação maior é com o processo e não com o produto; valoriza a perspectiva do participante; segue um caminho indutivo e seus dados são tendencialmente descritivos (BOGDAN; BIKLEN, 1994). Além disso, buscamos um aporte teórico que embasa, metodologicamente, pesquisas desenvolvidas com crianças.

Segundo Campos $(2008$, p. 35) "A criança faz parte da pesquisa científica há muito tempo, na condição de objeto a ser observado, medido, descrito, analisado e interpretado". Assim sendo, considerar a criança como sujeito ativo no processo de pesquisa ainda se constitui em um desafio aos estudos que privilegiam a escuta e as observações infantis, destacando-se o duplo significado dessas estratégias e procedimentos: além de sujeito investigado pelo pesquisador, ela - a criança - é também capaz de refletir sobre suas vivências, seu próprio modo de aprender, suas dificuldades, suas potencialidades, podendo se tornar investigadora e propositora de alternativas.

Nesse sentido, convém destacar que o compromisso ético-pedagógico e científico requer do pesquisador um exercício de alteridade que possibilite compreender as ações e os relatos infantis como fontes singulares de análise. Pretendemos dar a voz às crianças, e isso implica conceder-Ihes a palavra. Recorremos, então, a Bakhtin $(1988$, p. 36) que nos diz "a palavra é o fenômeno ideológico por natureza" para não cairmos na ingênua crença de que o dito é o retrato fiel da realidade. As respostas emitidas pelos sujeitos estão recheadas de múltiplas vozes, além disso,

[...] todo signo [...] resulta de um consenso entre indivíduos socialmente organizados no decorrer de um processo de interação [...] realizando-se no processo de relação social, 
todo signo é ideológico, e, portanto, também o signo linguístico, vê-se marcado pelo horizonte social de uma época e de um grupo social determinados (BAKHTIN, 1988, p. 44).

Entendemos, pois, que as respostas colhidas estão marcadas pelo contexto sociocultural em que os sujeitos se encontram, sendo produtos da interação destes com os outros.

Mudar a condição da criança como objeto de investigação para sujeito de investigação implica o estabelecimento de alguns critérios metodológicos. Seguimos então as orientações de Campos (2008, p. 38) que, entre muitos direcionamentos, nos diz: "Os tópicos abordados não devem ser impostos pelo pesquisador, mas este deve procurar partir das questões mais significativas do ponto de vista da experiência das crianças". 0 pesquisador também precisa levar em conta a desigual relação de poder entre adultos e crianças, combinada com as também desiguais relações étnicas e de gênero, que muitas vezes levam as crianças a fornecerem as respostas que julgam serem as esperadas e não aquelas que refletem honestamente seu ponto de vista. Uma das formas de tentar superar essa distância, sugerida em outra parte do texto, é colocar-se como parceiro, falando sobre si próprio, procurando mostrar-se como pessoa.

Para a seleção das escolas (lócus da pesquisa), foram consideradas as seguintes exigências: a) ser escola pública; b) ter turmas dos anos iniciais do Ensino Fundamental; c) aprovar a proposta de trabalho; d) possibilitar o acesso da pesquisadora.

A seleção dos sujeitos da pesquisa foi orientada pelos seguintes critérios: a) ser aluno do $1^{\circ}$ ou do $2^{\circ}$ ano do Ensino Fundamental da escola selecionada; b) aceitar espontaneamente ser sujeito da pesquisa; c) receber autorização, por escrito, dos seus pais ou responsáveis para participar do trabalho.

Na recolha dos dados, optamos pelos procedimentos: Observação, por concordar com Lüdke e André (1986) quando afirmam que essa possibilita um contato pessoal e estrito do pesquisador com o fenômeno estudado, além de ser útil para a descoberta de aspectos novos que estejam relacionados ao problema investigado; a entrevista semidiretiva, por esta permitir uma maior flexibilidade quando da explicitação do ponto de vista dos sujeitos da pesquisa, favorecendo a criação de um clima de confiança entre informado/informante, possibilitando que este se sinta mais à vontade para expressar-se sobre o tema proposto (TRIVIÑOS, 1987); e o questionário, como meio de conhecermos melhor os sujeitos de nossa pesquisa, pois ele é utilizado na descrição das características de um grupo (RICHARDSON et al., 1999). Para fins deste trabalho especificamente, fundamentamos nossa reflexão com base nos dados construídos, principalmente, através da observação e da entrevista.

Como desenvolvemos a pesquisa nos anos iniciais do Ensino Fundamental em escolas públicas, a primeira fase foi de contato com a direção da escola para auto- 
rização da pesquisa. Demos continuidade às demais providências para a realização do trabalho, iniciando pelo reconhecimento do ambiente em que seria desenvolvido o estudo para, em seguida, coletar/construir os dados.

Sequencialmente fizemos a análise de conteúdo dos dados apreendidos, cuja intenção "[...] é a inferência de conhecimentos relativos às condições de produção e de recepção das mensagens, inferência esta que recorre a indicadores (quantitativos ou não)" (BARDIN, 2008, p. 38).

Nessa investigação, foram entrevistadas dez crianças da escola Mauricio de Sousa ${ }^{1}$ e dez crianças da escola Monteiro Lobato, totalizando vinte sujeitos. Para orientar este relato, elaboramos um Quadro Guia, no qual visualizamos as principais categorias e subcategorias enfocadas na pesquisa. Destacamos, porém, que a discussão norteada pelo quadro categorial não está estruturada linearmente conforme o esquema apresentado no Quadro 1.

\begin{tabular}{|l|l|l|}
\hline Tema & Categorias & Subcategorias \\
\hline \multirow{2}{*}{$\begin{array}{l}\text { A educação } \\
\text { escolar na voz } \\
\text { de crianças }\end{array}$} & 1) 0 direito à educação & $\begin{array}{l}\text { 1.1 Escola como direito de todos } \\
\text { 1.2 Confronto: "letra" da lei e realidade }\end{array}$ \\
\cline { 2 - 3 } & $\begin{array}{l}\text { 2) Uma boa escola de } \\
\text { criança: caracteristicas }\end{array}$ & $\begin{array}{l}\text { 2.1 Diferenças com relação à escola de adultos } \\
2.2 \text { Finalidades } \\
2.3 \text { Aprendizagens mais relevantes } \\
\text { 2.4 Relação professor / crianças }\end{array}$ \\
\hline
\end{tabular}

Quadro 1: Categorias e subcategorias relativas ao tema A Educação Escolar na Voz de Crianças.

Fonte: As autoras (2009).

\section{Descrevendo o lócus}

A escola, inicialmente selecionada, foi a Mauricio de Sousa, cujo acesso foi facilitado, pela existência anterior de um projeto social desenvolvido pela pesquisadora no bairro onde a escola se localiza.

Iniciamos as observações sendo a pesquisadora apresentada à turma com o seguinte discurso: "Essa menina veio aqui observar a mim e a vocês"; percebemos, então, que a professora se sentiu inicialmente ameaçada, motivando-nos a pedir licença e a refazer a apresentação, dizendo: "Estou aqui para aprender sobre educação de crianças, com vocês." Nesse instante, pudemos perceber o olhar de curiosidade das crianças. Uma delas, rapida-

\footnotetext{
1 Visando manter em sigilo os nomes das instituições e dos sujeitos pesquisados, valorizando ainda os gêneros quadrinhos e literatura infantil, optamos por nomear escolas com nomes de representantes desses segmentos. Elegemos, então, para os nomes das escolas, os escritores Mauricio de Sousa e Monteiro Lobato. Para designar os sujeitos, seguiremos o mesmo pensamento, nomeando-os com os nomes de personagens dos referidos escritores.
} 
mente, aproximou-se e disse: "Eu não vou poder lhe ajudar, sou da turma dos burros!", mas sentou ao nosso lado, enquanto outro rapidamente retrucou: "Eu posso, já sei ler!". Em poucos minutos, verificamos que a construção do autoconceito daquelas crianças está relacionada ao fato de 'saber ou não saber ler'. A ideia negativa preconcebida sobre si mesmo nesse sentido pode afetar, num ciclo vicioso, o desempenho e atitudes discentes.

A turma parecia sempre muito agitada, e as aulas continuavam com ênfase na exposição oral e limitada participação dos alunos. Compreendemos que a falta de significado das atividades para os alunos interfere na motivação e esta afeta a quantidade e a qualidade do tempo em que as crianças estão dispostas a dedicar à aprendizagem, perdendo facilmente a concentração. Parece ainda haver uma distância entre o que se ensina e o que se aprende. Essa discrepância faz com que os alunos se envolvam em atividades e conversas paralelas e não pertinentes. Quando alguns alunos conversam, até mesmo sobre a atividade que estão fazendo, são repreendidos. Ao reagir desta forma com os alunos, a docente nos revela: "Tem gente de quem não aprendi nem o nome ainda, porque não preciso reclamar." Na fala da professora, aprender o nome do aluno é então sinal negativo, pois o nome é, geralmente, utilizado para insistir por silêncio ou por uma melhor conduta.

Os sujeitos expõem nas entrevistas seus sentimentos em relação à escola, referindo-se comumente às qualificações da professora. É importante ressaltar que para as crianças se sentirem mais confortáveis diante da pesquisadora, as entrevistas só se iniciaram após quatro semanas de observação. Além disso, estas foram feitas em sala isolada e registradas através de audiogravação para transcrições posteriores.

Do mesmo modo que não há como conceituar infância como uma ideia universal porque existem infâncias, não há como encontrar duas escolas absolutamente iguais em termos da prática pedagógica que desenvolvem, ainda que tenham a mesma estrutura física. Cada escola é única, representando uma construção social tecida pela comunidade escolar, refletindo em rotinas e características próprias. Nesse sentido, destacamos com o escritor português Miguel Torga (1996, p. 11) que diz: "Todos nós criamos um mundo a nossa medida e o certo é que há tantos mundos como criaturas. Luminosos uns, brumosos outros e todos singulares".

Assim sendo, embora as escolhas das duas escolas atendessem a critérios preestabelecidos e semelhantes, e suas localizações fossem muito próximas (mesma rua e mesmo bairro), os momentos observados, em cada uma das escolas, apresentaram características muito distintas e singulares.

Na Monteiro Lobato, o momento inicial era uma atividade muito especial. As crianças dirigiam-se as suas filas (organizadas por série) e alegremente encontravam seus colegas para juntos ouvirem as palavras da diretora. Após saudar os alunos com manifestações de felicidade por estarem iniciando um novo horário 
de aprendizagem, a diretora fazia alguns informes e convidava algumas crianças para leitura. Assistimos a uma dupla declamar um poema, uma pequena história e apresentação de fantoches. Na sequência, os grupos de alunos dirigiam-se às salas e, já acomodados, a professora pediu que nos apresentássemos. Agradecemos a oportunidade e explicamos os objetivos de ali estar, e uma criança rapidamente fala: "Bem que meu pai disse que mesmo os adultos estudam." Sentamos e observamos que, sem que a professora nada dissesse, os alunos já organizavam seu material e começavam a copiar a agenda do dia. Muitos dos alunos já se situavam rapidamente em que dia estavam e eram orientados a ajudar os colegas que sentiam dificuldade em localizar a data na agenda. A professora pergunta quem é o ajudante do dia e um aluno se apresenta; em seguida, começa a recolher os livros que não serão usados, enquanto a professora caminha pelas mesas, passando o visto nas tarefas, muitas vezes, aproveitando para retomar algumas questões individualmente.

Enquanto esse momento acontecia, um aluno aproveita para nos perguntar como viemos para a escola deles. Sem entender o que ele queria saber, indagamos - como assim? E ele diz, "Eu, por exemplo, venho na bicicleta de meu pai ou da minha mãe; na bicicleta de quem não tiver trabalho." Na verdade, o aluno queria saber qual a minha realidade social através do meio de transporte que eu utilizava. Demonstrava também, em sua fala, que já percebia o fantasma do desemprego que é parte dos diálogos e das preocupações infantis nessa comunidade.

A professora retomava a aula e questionava aos alunos - vocês sabem o que é cópia? Muitos queriam responder e ela orientava que falasse um por vez. Vejam a riqueza conceitual acerca de cópia: "É escrever igualzinho o do quadro ou do papel" "Serve para receitas, poemas de amor [...]". E o colega completa: "Se for poema, tem que escrever quem é o dono dele!", referindo-se ao autor.

Neste instante, a professora organiza as ideias com as inferências dos alunos e pede que abram o livro de Português na página que tem um poema e explica "Copiarei no quadro para que possamos observar a estrutura de um poema". Antes de terminar, ela observa que alguns alunos não trouxeram o livro e os organiza em duplas ou entrega livros sobressalentes, retirando-os do seu armário. A atividade acontece e a professora propõe a escrita de um texto narrativo no caderno de textos e orienta: "Lembrem-se dos parágrafos, letras maiúsculas quando necessário, do espaço entre as palavras". Para os alunos que diziam ainda não conseguirem produzir texto, a professora alertava: "Escreva do seu jeito! 2".

2 A professora observada parece conhecer o conceito psicogenético de produção espontânea, "escrita que a criança produz do seu jeito, o que não significa dizer que é de qualquer jeito”. A escrita espontânea, que não é resultado de cópia (nem atual nem posterior), é aquela que a criança produz tal como acredita que poderia ou deveria escrever um certo número de palavras. (FERREIRO, 1985, p. 16). 
A leitura e a escrita são atividades cotidianas e diversificadas nessa turma. Leitura silenciosa, em voz alta, reescrita de textos diversos, lendas, fábulas e até receitas.

Outros momentos de aprendizagem acontecem, em geral, com a participação maciça dos alunos. Nesse ambiente, testemunhamos práticas pedagógicas voltadas para a participação dos alunos e para o pensamento reflexivo, um nítido exemplo de que é possivel desenvolver excelentes trabalhos na escola pública.

Com relação às entrevistas, procuramos, nas duas escolas, seguir os mesmos procedimentos. No entanto, na Monteiro Lobato, observamos que as crianças se sentiram mais à vontade para falar, não necessitando muitas intervenções por parte da pesquisadora.

\section{Vozes infantis}

As falas das crianças retratam suas visões de mundo baseadas nas experiências vivenciadas. A seguir, elencamos alguns temas que foram explorados e que contemplam as vozes infantis, discutindo os aspectos que consideramos mais relevantes.

\section{Direito à educação}

Indagamos: "Todas as crianças têm direito a uma boa educação?" Em princípio, monossilabicamente, responderam apenas com sim ou não. Após a insistência da pesquisadora, os alunos da Escola Mauricio de Sousa demonstraram desconhecer que a educação é um direito garantido pela Constituição e alegam:

"Não, quem briga na escola não tem" (CASCÃO, 7 anos).

"Não, aqueles que só querem brincar não têm" (ROSINHA, 8 anos).

"Não têm aqueles que só fazem bagunça" (ANJINHO, 7 anos).

"Quem disse que a escola é ruim, a professora é ruim não tem" (FRANJINHA, 7 anos ).

Os parâmetros criados por essas crianças para ter ou não o direito à educação referendam o rigor infantil quanto à consequência dos atos dos colegas e estes não são vistos como consequência de algo negativo que possa ser gerador desses comportamentos. No entanto, alerta-nos Snyders (1993, p. 28): "Os métodos e as atitudes que a escola introjeta, servirão ao sucesso posterior do aluno e são os mesmos dos quais ele já necessita no presente para sentir alegria. A alegria presente da criança exige um certo autogoverno e um controle de suas ações.". Paralelamente, outros mostram-se bastante atentos às condições concretas em que vivem suas infâncias. Isso pode ser claramente constatado nas várias referências ao contexto, como ilustra a fala a seguir: 
"Tem muita criança que passa o dia na rua, que precisa ganhar dinheiro para ajudar a mãe" (CEBOLINHA, 8 anos).

Quando questionados se a lei que garante o direito a todos de fato acontece, obtivemos respostas sensatas, como:

"Não, tem muita criança que passa o dia na rua" (CEBOLINHA, 8 anos).

"Não, tem criança que passa dificuldade e não vai para a escola e outros não vão porque não querem" (CHICO BENTO, 8 anos).

"De jeito nenhum, tem muita criança que trabalha e passa o dia na rua" (CHICO BENTO, 8 anos).

"Tem muitas nas ruas, nos sinais, limpando os vidros" (PITECO, 9 anos).

"Tem umas que não tem dinheiro pra pagar pra ir para escola, pra comprar bolsa, lápis" (FRANJINHA, 7 anos).

É importante ressaltar que as falas retratam o meio circundante das crianças. Os motivos citados para a falta de acesso à escola são voltados, em geral, para a necessidade de produzir renda para suprir suas próprias necessidades e às de sua família. Fortalece-nos a convicção da estreita relação entre educação, exclusão social e desenvolvimento. As crianças trazem consigo não só sua realidade, mas também a daqueles que as rodeiam: uma realidade marcada pela ausência de direitos e que dificilmente será modificada na atual conjuntura social. As oportunidades que essas crianças já perderam são irrecuperáveis, totalmente, trazendo consequências para o seu desenvolvimento. Neste contexto, a escola sofre as consequências de sua incapacidade de proferir mudanças significativas na realidade da infância brasileira, enquanto também não há uma profunda mudança político-social que possibilite às crianças os recursos humanos e materiais para serem, simplesmente, crianças. 0 fato é que, em muitos momentos, a escola acaba confirmando e assegurando a estrutura social vigente.

0 direito subjetivo público à educação que lhe confere a possibilidade de acionamento direto, independente de norma infraconstitucional, também não é reconhecido pelas crianças da Escola Monteiro Lobato, as quais, quando questionadas, fazem muitas ressalvas:

"Todos têm direitos, menos os doentes." (EMÍLIA, 9 anos).

"Não são todas que têm direito porque tem umas que têm preguiça e não gostam de estudar." (BARNABÉ, 8 anos).

"0 povo que se droga não tem." (BARNABÉ, 8 anos). 
A educação é vista por eles não como um direito, mas como um mérito a quem merece. Os doentes e os usuários de drogas aparecem como elementos nocivos desconsiderando que "a dignidade humana, pensada como autonomia ética de seres humanos socialmente situados, é o valor que fundamenta todos os demais direitos" (KOERNER, 2005, p. 72). Seriam então, para as crianças, os preguiçosos e doentes, excluídos da dignidade humana? Ou estes são considerados seres humanos de uma classe inferior? Os estudos piagetianos sobre o juizo moral apontaram que é a partir dos sete anos "[...] que se começa a desenvolver a ideia de justiça. E esta ideia de justiça não está baseada em autoridade adulta, mas muitas vezes existe à custa dessa autoridade. Está baseada nas relações de igualdade entre as próprias crianças" (PIAGET apud EVANS, 1973, p. 78). 0 fato é que a promoção do bem de todos sem preconceito de origem, raça, sexo, cor e quaisquer outras formas de discriminação, prevista no artigo $3^{\circ}$ da Constituição, também não encontra eco no pensamento infantil, embora "o caráter comunitário da constituição, assim como os direitos de cidadania explicitados por ela universalizados significam que o quadro legal da 'cidadania regulada' foi superado" (KOERNER, 2005, p. 77). Significa, então, que é a sociedade que deslegitima os direitos humanos, seja por desconhecimento ou por falta de ação, distancia as prerrogativas legais da realidade, desfavorecendo, consequentemente, aqueles que precisam. 0 proclamado ensino para todos refere-se ao

[...] direito de todas as crianças e todos os jovens irem para a mesma escola, até mesmo com o uniforme que disfarça as diferenças. Essa seria, por assim dizer, a primeira exigência quando se pensa a educação como direito público (BOTO, 2005, p. 118).

É claro que, quando a autora propõe a mesma escola, está se dirigindo para a sonhada igualdade de oportunidade para todos, pois sabe das desigualdades encontradas na educação das crianças. A diversidade esperada e construtiva nas instituições educativas não é antônimo de igualdade de condições, pois esta se refere à pluralidade metodológica, de pensamentos, de organização e não às carências encontradas em alguns ambientes.

\section{Escola para criança: características}

As concepções de qualidade referentes à escola dirigem-se ao objetivo principal da instituição educativa: local para ensinar e aprender. As respostas a essas questões retratam a visão das crianças, da Escola Mauricio de Sousa quanto às caracteristicas essenciais de uma boa escola para crianças:

"Tem que ter brinquedo, boneca pra menina e boneco pros meninos e dever pra gente fazer..." (PITECO, 9 anos).

"Pra estudar, brincar" (FRANJINHA, 8 anos).

"É ter brinquedo, aprender a ler e a escrever" (ROSINHA, 8 anos). 
As crianças parecem reconhecer que o brinquedo é essencial para o seu desenvolvimento e enfatizam a presença deste numa boa escola infantil. Na realidade, o parque, os brinquedos constituem parte da infraestrutura básica que deveria existir em qualquer escola para crianças. Tanto é que, na percepção dos sujeitos, a maior diferença entre escola de criança e de adulto "é que tenha brinquedo para a gente brincar" (PITECO, 9 anos). 0 brincar é uma dimensão bastante valorizada e estudada pela literatura, aparecendo com destaque na voz das crianças que demonstram o prazer que esta experiência proporciona. Não há uma entrevista, sequer, que não tenha referência ao brincar, seja mencionado como uma caracteristica essencial para uma boa escola ou na demonstração de sentimento de falta quando perguntados sobre o que gostariam que existisse na escola. Nessa instituição, não havia brinquedos e as oportunidades de brincar eram muito limitadas. Outro elemento citado para diferir da escola de adulto é o nivel de complexidade e tamanho das tarefas "porque é mais dificil" ou porque "os adultos fazem mais dever que as crianças" (ROSINHA, 8 anos). Vale salientar que as experiências piagetianas demonstraram que é no período operacional concreto - fase em que se encontram os sujeitos - que se desenvolve a capacidade de utilizar termos comparativos.

Não são diferentes as opiniões das crianças da Escola Monteiro Lobato quando se referem às características de uma boa escola para criança. 0 essencial é "ter parque muito grande, pode ajeitar esses brinquedos que tá quebrado" (EMÍLIA, 9 anos). Vygotsky (1998, p. 135) dedicou um capítulo do seu livro "A formação social da mente" ao papel do brinquedo no desenvolvimento e pontua:

É enorme a influência do brinquedo no desenvolvimento [...]. É no brinquedo que a criança aprende a agir numa esfera cognitiva, ao invés de numa esfera visual externa, dependendo das motivações e tendências internas, e não incentivos fornecidos pelos objetos externos.

E complementa:

0 brinquedo fornece ampla estrutura básica para mudanças das necessidades e da consciência. A ação na esfera imaginativa, numa situação imaginária, a criação das intenções voluntárias e a formação dos planos da vida real e motivações volitivas - tudo aparece no brinquedo, que se constitui, assim, no mais alto nível de desenvolvimento (VYGOTSKY, 1998, p. 135).

Para as crianças, escola tem ainda que ser um espaço para "estudar, escrever, ler e pintar. E tem que ter uma boa professora" (ROSINHA, 9 anos). Observamos que, embora o brinquedo e as questões estruturais tenham um lugar especial, as falas das crianças transcendem os aspectos físicos e demonstram consciência de outros elementos, também importantes, como o estudo, a leitura, chegando até a citar a necessidade da qualificação dos professores. Quanto às diferenças entre escola de criança e escola de adultos, Pedrinho (9 anos) explica com propriedade "Escola de criança tem que ter coisas de crianças e para 
crianças, como livro de criança, brinquedo de criança, aula para criança, professora para criança". Pedrinho (9 anos) alerta para que a especificidade da infância seja valorizada. Na ótica dessa criança, deve ser assegurado o direito de ter um espaço próprio e estruturado para suas singularidades, além de aulas especiais e professoras que saibam lidar com crianças. Essa fala revela ainda o desejo infantil de que as instituições se ajustem às necessidades de suas etapas de vida, tornando o ambiente atrativo e motivador, caracteristicas realmente importantes para que, de fato, aconteçam aprendizagens significativas. Por outro lado, Visconde, 9 anos, diz: "Adulto é para ir para a escola para saber coisas sobre a profissão que escolheu", já que estão ali apenas para receber informações sobre suas profissões. E os adultos que, sequer, tiveram o direito de serem alfabetizados em idade própria? Estes, embora estivessem presentes em observações informais das crianças, no momento das entrevistas foram esquecidos, como se as respostas deles devessem estar focadas em como deveria ser a escola para adultos e não como muitas vezes eles a veem.

0 conceito poético de Barnabé, 8 anos, explica a diferença: "Mais ou menos assim... escola de criança é colorida e a de adulto é preta e branca.". Podemos entender nessa fala a importância da alegria e vivacidade infantis expressas em cores. Podemos lembrar ainda da mutabilidade e mobilidade infantis, comparadas com a estabilidade adulta. Para os adultos, esses elementos não são essenciais porque "Eles leem muito no quadro, nos livros e também conversam muito" (EMÍLIA, 9 anos).

Ilustramos nossa preocupação com o pensamento esperançoso expresso por Snyders (1993, p. 12):

Eu gostaria que os testemunhos de alegria na escola aparecessem como indices precursores, propondo através de exceções o que a escola poderia vir a ser em geral. Ou melhor, que esses testemunhos fossem pontos de apoio para que isso ocorresse, assim como certos homens são os precursores do que o homem pode se propor.

Infelizmente, muitas escolas brasileiras ainda não oferecem espaços adequados para a educação de crianças, reforçando com sua organização a ideia de que um bom espaço escolar seria aquele em que os professores tivessem facilidade para controlar e dirigir seus alunos. Reconhecemos que mudanças existem: os estrados em sua maioria foram retirados e os cantos de castigo desapareceram, pelo menos em sua concretude. No entanto, as carteiras enfileiradas ainda são o retrato da sala de aula no nosso país. Essa forma de organização valoriza o trabalho individualizado e centrado no professor, gerando, em algumas situações, a imobilidade do aluno. Observamos, na Escola Mauricio de Sousa, que as poucas tentativas de reorganização das salas, unindo os alunos em duplas ou em pequenos grupos, causaram dificuldades para a professora manter 0 desejado silêncio do grupo. Entendemos que esses fatos podem ser justificados com outra observação: trata-se de uma prática docente centrada na professora, que se 
desorganiza quando algo está "diferente", causando-Ihe transtornos e motivando-a para retornar à organização espacial costumeira e mais tranquilizadora. É evidente a dificuldade da professora em trabalhar com corpos que se movimentam, bocas que falam, cabeças que pensam, portanto nos parece que para ela o espaço deve ser mais um elemento que favoreça o silêncio e a passividade corporal e intelectual dos alunos. Paralelamente à sala de aula, as demais iniciativas dessa escola, inclusive os externos, da fachada ao pátio, não lembram um espaço voltado para a infância, talvez por precisar de uma arquitetura séria, que abrigue, no mesmo local, crianças, jovens e adultos.

0 espaço físico é o cenário que emoldura as relações com o mundo e as pessoas, sendo o reflexo material de todo um sistema de valores, costumes e crenças. Considerando a importância do meio para o desenvolvimento dos alunos, podemos inferir que a forma como organizamos o ambiente irá repercutir, significativamente, nas aprendizagens dos alunos. Ambiente pouco atrativo torna-se também pouco convidativo às aprendizagens infantis. $A$ pobreza de materiais, a dificuldade de recursos para investir em materiais lúdicos, não foram justificativas para a Escola Monteiro Lobato garantir a valorização da infância através de suas ambientações. Em cada projeto que estava sendo desenvolvido, a escola vestia-se de enfeites que caracterizassem aquelas novas aprendizagens. 0 planejamento e a execução eram pensados e desenvolvidos através da parceria entre a direção, coordenação, professores e alunos. Havia uma sensação de acolhimento às crianças, desde a entrada. A decoração tinha uma perspectiva didática e os ambientes eram muito bem conservados. A ludicidade estava presente em todos os lugares, incluindo plaquinhas que apontavam para os diferentes ambientes. Dificil não comparar com a "nudez" das paredes da Escola Mauricio de Sousa e a frieza dos espaços que apenas objetivava ser útil e seguro. Podiamos questionar: útil para quê? Para receber informações e reproduzi-las? Seguro para limitar desafios?

Entendemos que a Escola para Criança tem que ser agradável, estimulante e desafiadora de ações, posturas e ideias. Tem que ter cara de criança, materiais, cores, alegria, sonoridade, características da infância. Um espaço de alegria compartilhada por alunos e professores.

\section{Aprendizagens mais relevantes}

Para os alunos da Escola Mauricio de Sousa, a principal aprendizagem na escola é evidenciada pela totalidade dos sujeitos: a aprendizagem da leitura e da escrita,que se refere ao desejo desse conhecimento como instrumento importante para atividades posteriores, ou como prova das suas possibilidades de aprendizagem. Nesse sentido, vejamos o que nos dizem as crianças:

"Quando a gente vem pra escola e aprende a ler, vê como vai ser o mundo daqui pra frente [...]. Até pra apanhar lixo a gente tem que saber ler" (MÔNICA, 8 anos).

"Quem não sabe ler é burro" (FRANJINHA, 8 anos). 
Diferentes autores assinalam aspectos importantes sobre o processo de aprendizagem da leitura. Recorremos a Smith (2003, p. 15-16), que, através de seu embasamento científico, explica:

Não há nada de especial na leitura, a não ser tudo que nos possibilita fazer. 0 poder que a leitura proporciona é enorme, não somente por dar acesso a pessoas distantes e possivelmente mortas há muito, mas também por permitir o ingresso em mundos que, de outro modo, não seriam experimentados, que, de outro modo, não existiriam. Ler não demanda qualquer talento especial ou um desenvolvimento único do cérebro. Qualquer criança que possa ver bem o bastante para distinguir um rosto de outro. Em uma fotografia, e que possa entender a linguagem familiar de sua família ou amigos, possui a capacidade para aprender a ler.

Embora não tenham expressado literalmente, o que eles demonstram é o desejo de aprender para ter um futuro melhor, sendo a leitura o principal veículo. De fato, como nos assegura Ferreiro (2007), a alfabetização é a mais básica de todas as necessidades de aprendizagem. Não temos dúvida do sentimento de impotência e menos valia gerados pela não alfabetização em idade própria. Mesmo assim, muitos consideram difícil ou quase uma adivinhação como a fala retrata a seguir:

"Aprender a ler é pegar o caderno e ler e saber se é ou não é" (CEBOLINHA, 8 anos).

Sentimos a falta de significado da aprendizagem da leitura e da escrita expressa na fala do aluno. Para Smith (2003, p. 16):

A natureza objetiva da leitura é central, não só porque normalmente as pessoas leem por uma razão, seja para encontrar um número telefônico, ou para saborear um romance, mas porque a compreensão que um leitor deve trazer para a leitura somente pode ser manifestada através das intenções do próprio leitor. Uma pessoa que não põe qualquer finalidade em sua leitura pode trazer nada a esta, e a atividade está destinada a ser inútil.

Outros falam da persistência para a aprendizagem da leitura: "Aprende a ler tentando, pegando o livro tentando e tentando ler" (CASCÃO, 7 anos).

Ferreiro (2007, p. 17) sugere que, antes de qualquer outra reflexão, "Devemos perguntar-nos quais são os objetivos da alfabetização inicial?" E alerta:

No decorrer dos séculos, a escola (como instituição) operou uma transmutação da escrita. Transformou-a de objeto social em objeto exclusivamente escolar, ocultando ao mesmo tem- 
po suas funções extraescolares: precisamente aquelas que historicamente deram origem à criação das representações escritas da linguagem. É imperioso (porém nada fácil de conseguir) restabelecer, no nível das práticas escolares, uma verdade elementar: a escrita é importante na escola porque é importante fora da escola, e não o inverso (FERREIR0, 2007, p. 20-21).

Magda Soares (2008, p. 74) parece dialogar com Ferreiro (2007) e complementa:

As crianças das camadas populares que, em geral, não convivem com livros nem têm quem Ihes leia histórias (já que o livro é objeto cultural sonegado às camadas populares), mas que fazem, certamente, suposições sobre as funções da escrita, experimentam o conflito entre as suposições e o que a escola thes apresenta. Quando escrevem, buscam obedecer ao modelo.

A leitura e a escrita assumem para essas crianças exclusivamente a função instrumental. Elas demonstram desconhecerem outras possibilidades, como instrumento de expressão. Nessa perspectiva, Magda Soares (2008, p. 23) nos adverte:

Esse significado instrumental atribuído à alfabetização pela escola serve, naturalmente, apenas às classes privilegiadas, para as quais aprender a ler e a escrever é, realmente, não mais que adquirir um instrumento de obtenção de conhecimentos, já que, por suas condições de classes, já dominam a forma de pensamento subjacente à língua escrita, já têm o monopólio da construção do saber considerado legítimo e já detêm o poder político. Para as classes dominadas, o significado meramente instrumental atribuído à alfabetização, esvaziando-a de seu sentido político, reforça a cultura dominante e as relações de poder existentes, e afasta essas classes da participação na construção e na partilha do saber.

A escrita e a leitura parecem para as crianças como processos isolados. Quando questionados se sabem ler, as respostas são 'sei', 'não' e 'quase sei'. Mas quanto à escrita, 100\% consideram dominá-la, respondendo sempre a palavra "Sei". Franjinha (7 anos) nos explica: "Escrever é só pouca coisa, é só desenhar". A escrita aparece na visão das crianças, como pré-requisito para a leitura, "para aprender a ler tem que saber escrever e prestar atenção" (ROSINHA, 8 anos).

Na Escola Monteiro Lobato, as crianças confirmam que a aprendizagem mais importante da escola é "ler e escrever" (EMÍLIA, 9 anos). Sendo assim, o motivo de vir à escola é: "Estudar e aprender a ler e escrever" (NARIZINHO, 9 anos), porque "se você crescer e você não sabe ler, você não vai ter nenhum trabalho" (VISCONDE, 9 anos) e nos ensinam ainda como se aprende: "se aprende a ler, lendo e a escrever, 
escrevendo. Primeiro a gente escreve errado assim do nosso jeito, ai depois aprende a escrever certo". "O segredo é descobrir que as letras juntam-se e formam sons, aí as silabas também se juntam e formam as palavras" (VISCONDE, 9 anos).

A perspectiva construtivista tem se dedicado a evidenciar as hipóteses das crianças durante o processo de construção do conhecimento. Quanto à alfabetização, autoras que trabalham nessa perspectiva apresentam uma série de regularidades entre todas as crianças, assim, explicadas por elas:

A criança constrói hipóteses, resolve problemas e elabora conceituações sobre o escrito [...]. As hipóteses que as crianças desenvolvem constituem respostas a verdadeiros problemas conceituais, semelhantes aos que os seres humanos se colocaram ao longo da história da escrita [...]. 0 desenvolvimento de hipóteses ocorre por reconstruções (em outro nível) de conhecimentos anteriores, dando lugar a novas construções (assim acontece, por exemplo, com o conhecimento sobre as palavras, as expressões da linguagem, a forma e o significado do signo) (TEBEROSKY; COLOMER, 2003. p. 45).

A aquisição da escrita faz parte do processo geral de aquisição da linguagem. 0 contato da criança com a escrita é iniciado, ou deveria ser, quando ainda não compreendeu de todo a linguagem oral, fazendo com que a criança reflita sobre esta, quando está escrevendo e inicie a formulação de hipóteses até o entendimento de que, no nosso sistema de escrita, as relações entre escrita e pauta sonora acontecem entre grafema/som e não entre grafema/silaba.

Os meios para as explorações da leitura/escrita são citados, como as revistas em quadrinhos, historinhas. Graças a essas possibilidades, essas crianças demonstram fazer uso cotidiano da língua escrita, facilitando a compreensão da função social desta, chegando a explicar a função de comunicação que também possuem. "Aprende a ler começando pelos desenhos como as letras, sabendo que elas vão formar sons para falar alguma coisa para alguém. Antigamente os desenhos eram feitos nas pedras" (ROSINHA, 8 anos).

\section{Relação professor / criança}

Quando questionados sobre o que é ser uma boa professora para crianças, os alunos da Escola Mauricio de Sousa referem-se à forma das professoras dirigirem-se a eles.

"Uma boa professora tem que falar baixo e deixar a gente falar" (PITECO, 9 anos).

"Deve ser calma, não tem que reclamar toda hora" (CASCÃO, 7 anos).

"Para ensinar a gente mais o dever, mais a ler e escrever" (MÔNICA, 8 anos). 
"Sem dizer que tá tudo errado, vá fazer tudo de novo" (FRANJINHA, 7 anos).

"Não chamar a pessoa de burro" (PITECO, 9 anos).

"Tem que ensinar muito, até todo mundo aprender, até os burros" (CHICO BENTO, 8 anos).

Verificamos o clamor das crianças pela paciência, tranquilidade, valorização da professora, além do apelo pela participação na aula. Nesse sentido, Kostiuk (2003, p. 25) indica:

0 ensino nas escolas não pode limitar-se apenas a transmitir ao discípulo determinados conhecimentos, a formar um mínimo de aptidões e hábitos. A sua tarefa é desenvolver o pensamento dos alunos, a sua capacidade de analisar e generalizar os fenômenos da realidade, de raciocinar corretamente.

Sabemos que, sem participação ativa do aluno, esse propósito se distancia da realidade. Desse modo, caberia ao professor organizar sua prática distante da simples coerção disciplinadora, baseada em situações em que o aluno possa exercer sua criatividade, defender e confrontar suas ideias.

Quando Piteco qualifica uma professora por não chamar a pessoa de burro, abrese uma ideia que, para ele, essa possibilidade existe. Nesse caso hipotético, além da absurda falta de respeito, estaria se ferindo o direito subjetivo "frente ao qual todas as pessoas são sujeitos passivos, obrigando-se a zelar pela integridade e segurança mútua" (FERREIRA 2004, p. 73). Isso gera um dano moral inquestionável ao aluno, pois seria "capaz de causar transtornos de tal ordem que imponha à vitima um sofrimento injusto, real e afetivo" (FERREIRA 2004, p. 74). Outro aluno utiliza a mesma terminologia quando fala da persistência que a professora deve ter para ensinar a todos "até os burros", como se ser burro fosse um possivel e inevitável diminutivo de alguns seres humanos. Snyders (1993, p. 61) analisa: "muitas vezes, os jovens aceitam, a respeito de si mesmos e de sua geração, muitas ideias e juízos que lhes são desfavoráveis e que, em última instância, justificariam sua autodepreciação". Gimeno Sacristán e Pérez Gómez (1998, p. 16) parecem estar discorrendo exatamente sobre o assunto, quando afirmam: "Dessa forma, aceitam-se as caracteristicas de uma sociedade desigual e discriminatória, pois aparecem como o resultado natural e inevitável das diferenças individuais evidenciadas em capacidades e esforços.". Preocupa-nos que o processo educacional que deveria ter a função social de oferecer possibilidades de crescimento, esteja minando as perspectivas dos menos favorecidos, estimulando-os a aceitarem as arbitrariedades que o sistema capitalista propõe e a elas se adaptarem. A função docente não pode aceitar o "jogo do dominador" e justificar suas falhas e ausência de motivação pela reconhecida expropriação dos seus direitos, pois assim estaria, como nos diria Paulo Freire, oprimindo seus alunos. 
Em sala de aula, a fala do professor é compreendida em muitos momentos como sinônimo de bagunça. Recorremos a Vygotsky (2004) para enaltecer a importância da interação social no desenvolvimento humano. Para ele, a linguagem é o que ajuda a criança a direcionar o pensamento.

É preciso registrar que, nessa escola, em especial, ficou patente a influência que as experiências oferecidas às crianças têm na qualidade de sua expressão oral. De modo geral, sabemos que as crianças que têm oportunidade de ouvirem histórias, participarem de diálogos e que são estimuladas a emitirem opiniões desenvolvem um vocabulário mais vasto e utilizam frases mais longas e elaboradas. Como, infelizmente, não é essa a prática que predomina no ambiente pesquisado, as frases da maioria das crianças ouvidas eram muito curtas, sendo boa parte restrita a apenas uma palavra. Observamos que a oralidade não estava sendo bem desenvolvida nessa escola, resultando no empobrecimento das possibilidades comunicativas das crianças.

Magda Soares (2003, p. 60, grifo do autor) alerta para a consequência da falta de espaço de comunicação das crianças na escola:

Não é difícil inferir de tudo isso mais uma explicação
linguística para o fracasso das camadas populares na
escola: enquanto as crianças das classes favorecidas
vêem essa instituição como um espaço e um tempo de
aprendizagem, já que, para elas, a língua é aí usada pre-
dominantemente com a função representativa, as crian-
ças das camadas populares a vêem como o espaço e
tempo de "modelagem" de seus comportamentos soci-
ais, pois, para elas, a língua tem, na escola, uma função
predominantemente reguladora.

A disposição da classe, com as cadeiras sempre enfileiradas, resulta na falta de espaço para a movimentação corporal. Esse aspecto não foi percebido pelas crianças como algo relevante para a qualidade da escola.

$\mathrm{Na}$ Escola Monteiro Lobato, as caracteristicas de uma boa professora podem ser resumidas na fala de Emilia, 9 anos: "Ela deve ser boa e educada". Pedrinho, 9 anos, complementa: "Ela tem que estudar para ensinar a gente, tem que saber das coisas para poder ensinar, tem que saber falar e ouvir."

As crianças percebem a importância da capacitação docente para o exercício da função e que o conhecimento do conteúdo conceitual é uma condição para a boa docência. Sabemos que a formação docente pode ser caracterizada por duas fases distintas: a formação inicial e continuada, "que devem ser vistas 
como um continuum no sentido de serem complementares e não excludentes" (FERREIRA, 2008. p. 90). Nesse sentido, o Estatuto da Criança e do Adolescente é a lei que regulamenta também a relação professor/aluno, pois como afirma Ferreira (2008, p. 92), "estabeleceu diretriz para a questão educacional da criança e do adolescente, estabeleceu obrigações aos professores e contemplou consequências administrativas e penais em caso de ausência de sua atuação." E complementa o autor: "Nessa direção, a Lei Menorista deve ser considerada na formação do professor (inicial ou continuada) para melhor desempenho de seu mister. Sua análise vem reforçar o novo perfil do profissional da educação." A professora observada nos contou dos diversos cursos de que já tinha participado neste ano e, de fato, suas atitudes demonstravam relação com o que tinha aprendido, sendo capaz de desenvolver um trabalho sério e coerente com os propósitos estudados. A convicção do seu papel era também percebida nas situações de partilha de conhecimento e nas relações cordiais e afetivas que mantinha com seus alunos. Freire (2007, p. 41) lembra que:

A natureza formadora da docência, que não poderia reduzir-se a puro processo técnico e mecânico de transferir conhecimentos, enfatiza a exigência ético-democrática do respeito ao pensamento, aos gostos, aos receios, aos desejos, à curiosidade dos educandos.

Na formação profissional, o professor deverá ser sensibilizado para a importância do diálogo com o aluno. Falar e ouvir são características do diálogo, essencial para o processo de ensino-aprendizagem, pois implica troca de ideias para a solução de problemas. Segundo Vasconcellos (2007, p. 77):

Se queremos uma escola libertadora, é absolutamente decisivo que os alunos assumam seu papel de sujeitos, que sejam protagonistas do seu processo de educação, superando a longa tradição da maquinaria escolar que tenta, de todas as formas, ainda que com a melhor das boas intenções, reduzi-los a meros 'receptáculos'. Sendo assim, o aluno tem preservado o direito de participar de sua vida escolar e o professor exime-se da função de cercear a voz do aluno e passa a valorizá-la, aproveitando este canal para aproximálos dos objetivos formativos e educacionais, trazendo, para ambos, crescimento mútuo.

Desse modo, os professores precisam refletir quanto à sua maneira de conceber a criança que aprende, ou seja, uma criança que pensa, que fala, que constrói, que compara, que inventa. Para, assim, estabelecerem uma relação de confiança e respeito mútuo. 


\section{Fatos e fundamentos: (in)conclusões}

0 direito das crianças à escola inclui não só o acesso, mas uma educação de qualidade que considere as necessidades infantis, entre as quais a de ser ouvida e respeitada. Segundo Ferreira (2009), um dos significados da palavra Infância em latim é "ainda não falar"; no entanto, as crianças interiorizam o vocabulário e as regras de sua língua nativa, na maioria das vezes, até os cinco anos de idade, sendo capazes de expressarem suas ideias e opiniões.

Assim sendo, para atingir a qualidade desejada, que respeite os propagados direitos das crianças, é indispensável que esta qualidade seja construída com a participação ativa de todos os protagonistas envolvidos, o que inclui desde autoridades responsáveis até as crianças, sendo estas evidenciadas na nossa pesquisa como os principais atores deste cenário.

Os resultados obtidos na investigação não pretendem oferecer uma avaliação da qualidade das instituições visitadas. Não foi esse o objetivo da pesquisa. Desse modo, as características das instituições incluídas são descritas, visando contextualizar os dados obtidos através das vozes infantis. No entanto, não podemos negar a surpresa quanto às diferenças dos dois lócus desta pesquisa.

Embora as instituições pesquisadas estejam localizadas a um $\mathrm{km}$ uma da outra, sendo as duas organizações públicas, suas formas de conceber e fazer educação são distintas. Enquanto na Mauricio de Sousa as dificuldades encontradas justificavam os fracassos produzidos, na Monteiro Lobato o trabalho pedagógico existia a despeito de qualquer limitação. Se em uma não havia respeito maior à infância, verificado na imposição autoritária de silêncio, na ausência de brinquedos e na falta de espaços próprios, na outra, os brinquedos existiam (ainda que doados pela comunidade ou construídos na própria Escola) e a decoração didática também deixava a Escola mais infantil, tornando-se um ambiente muito agradável. A diversidade é algo esperado entre as escolas, mas nos preocupa na medida em que uma delas revela condições limitadas de atendimento para o objetivo a que se propõe.

As concepções, aspirações e opiniões das crianças não são formuladas ao acaso; ao contrário, dependem do ambiente social e cultural em que vivem e delas compartilham, inclusive, a própria escola. Quando são estimuladas a refletir e questionar, elas demonstram que, além de estarem bastante alertas às condições concretas em que vivem suas infâncias, conseguem expressar suas ideias com propriedade. Isso pode ser constatado nas várias referências à preocupação com o futuro. Assim, as opiniões das crianças reforçam a ideia de que, como construção social, a infância é sempre contextualizada em relação ao tempo, ao local e à cultura, variando segundo as condições vivenciadas. 
As crianças expressam o desejo infantil de que a escola tivesse brinquedos. A ênfase no brinquedo como elemento essencial e prazeroso para as aprendizagens escolares esteve presente na fala de todos os sujeitos, especialmente na escola em que estes eram quase inexistentes, tornando ainda mais distante o espaço que separa o desejo das crianças e 0 que a sociedade thes oferece. As observações sobre a professora na Mauricio de Sousa são pautadas em caracteristicas simples como ser calma, não gritar, enquanto na Monteiro Lobato, percebemos uma visão mais ampla, referindo-se até à capacitação docente. A aprendizagem mais importante é para todos os sujeitos a aprendizagem da leitura, diferindo quanto à ideia de como se aprende. A aprendizagem da língua escrita na nossa sociedade letrada é, para essas crianças, questão de sobrevivência, o que traz consigo a consciência de uma divisão nas turmas: "Os que sabem ler, ou seja, os inteligentes e os que não sabem - a turma dos burros." Quanto ao direito à educação, a maioria das crianças não o compreende como uma regra a ser efetivada, mas como um mérito a quem merece e uma punição aos que fogem das regras de conduta em que acreditam.

A capacidade de julgar, analisar, criticar das crianças está demonstrada, o que nos leva a concluir que a escuta infantil deve possibilitar mudanças na prática docente e, quiçá, na própria educação das crianças.

\section{Referências}

ALARCÃO, I. Escola reflexiva e nova racionalidade. Porto Alegre: Artmed, 2001.

ARIĖS, P. História social da criança e da familia. 2. ed. Rio de Janeiro: Guanabara Koogan, 1986.

ASSMANN, H. Reencantar a educação: rumo à sociedade aprendente. 9. ed. Petrópolis, RJ: Vozes, 2007.

BAKHTIN, M. Marxismo e filosofia da linguagem. Trad. Michel Lahud; Yara Frateschi Viera. 4. ed. São Paulo: Hucitec, 1988.

BARDIN, L. Análise de conteúdo. 4. ed. Lisboa: Edições 70, 2008.

BOGDAN, R.; BIKLEN, S. Investigação qualitativa em educação: uma introdução à teoria e aos métodos. Porto: Porto Ed., 1994. (Coleção Ciências da Educação).

BOTO, C. A educação escolar como direito humano de três gerações: identidades e universalismos. In: SCHILLING, F. Direitos humanos e educação: outras palavras, outras práticas. São Paulo: Cortez, 2005.

BRASIL. Lei no 8.069, de 13 de julho de 1990. Estatuto da Criança e do Adolescente. São Paulo: CBIA-SP, 1991. 
CAMPOS, M. M. Por que é importante ouvir a criança?: a participação das crianças pequenas na pesquisa científica. In: CRUZ, S. H. V. A criança fala: a escuta de crianças em pesquisas. São Paulo: Cortez, 2008.

EVANS. R. Piaget: o homem e as suas ideias. Lisboa: Universidade Aberta Socicultur, 1973.

FERREIRA, D. Ensino público e ensino privado: diferenças constitucionais. In: (Coord.). Direito educacional em debate. São Paulo: Cobra Ed., 2004.

FERREIRA, L. A. M. O Estatuto da Criança e do Adolescente e o professor: reflexos na sua formação e atuação. São Paulo: Cortez, 2008.

FERREIRA, N. Aprendendo a falar. Revista de Língua Portuguesa, São Paulo, n. 15, p. 9-11, jan. 2009.

FERREIRO, E. Com todas as letras. 14. ed. São Paulo: Cortez, 2007.

FERREIRO, E. Psicogênese da língua escrita. Porto Alegre: Artes Médicas, 1985.

FREIRE, P. Pedagogia da autonomia: saberes necessários à prática educativa. São Paulo: Paz e Terra, 1996.

. Política e educação. 8 ed. Indaiatuba, SP: Villa das Letras, 2007. (Coleção Dizer a Palavra).

FORMOSINHO, J. 0.; KISHIMOTO, T. M.; PINAZZA, M. A. Pedagogia(s) da infância: dialogando com o passado: construindo o futuro. Porto Alegre: Artmed, 2007.

GIMENO SACRISTÁN, J.; PÉREZ GÓMEZ, A. I. Compreender e transformar o ensino. 4. ed. Porto Alegre: Artmed, 1998.

KOERNER, A. A cidadania e o artigo $5^{\circ}$ da Constituição de 1988. In: SCHILLING, F. Direitos humanos e educação: outras palavras, outras práticas. São Paulo: Cortez, 2005.

KOSTIUK, G. S. Alguns aspectos da relação reciproca entre educação e desenvolvimento da personalidade. In: LEONTIEV, A. et al. Psicologia e pedagogia: bases psicológicas da aprendizagem e do desenvolvimento. São Paulo: Centauro, 2003.

KRAMER, S.; LEITE, M. I. Infância: fios e desafios da pesquisa. 7. ed. Campinas, SP: Papirus, 2003. (Série Prática Pedagógica). 
LÜDKE, M.; ANDRÉ, M. E. D. A. Pesquisa em educação: abordagens qualitativas. São Paulo: EPU, 1986. (Temas Básicos de Educação e Ensino).

PIAGET, J. A linguagem e o pensamento da criança. São Paulo: Martins Fontes. 1980.

RICHARDSON, R. J. et al. Pesquisa social: métodos e técnicas. 3. ed. São Paulo: Atlas, 1999.

SMITH, F. Compreendendo a leitura: uma análise psicolingüistica da leitura e do aprender a ler. 4. ed. Porto Alegre: Artmed, 2003.

SNYDERS, G. Alunos felizes: reflexão sobre a alegria na escola a partir de textos literários. Tradução Cátia A. Pereira da Silva. 4. ed. Rio de Janeiro: Paz e Terra, 1993.

SOARES, M. Alfabetização e letramento. 5. ed. São Paulo: Contexto, 2008. Letramento: um tema em três gêneros. 2. ed. Belo Horizonte: Autêntica, 2003.

TEBEROSKY, A.; COLOMER, T. Aprender a ler e a escrever: uma proposta construtivista. Porto Alegre: Artmed, 2003.

TORGA, M. A criação do mundo. Rio de Janeiro: Nova Fronteira, 1996.

TRIVIÑOS, A. N. S. Introdução à pesquisa em ciências sociais: a pesquisa qualitativa em educação. São Paulo: Atlas, 1987.

VASCONCELLOS, C. S. Coordenação do trabalho pedagógico: do projeto político-pedagógico ao cotidiano da sala de aula. 8. ed. São Paulo: Libertad, 2007.

VYGOTSKY, L. S. A formação social da mente: o desenvolvimento dos processos psicológicos superiores. 6. ed. São Paulo: Martins Fontes, 1998.

. Pensamento e linguagem. São Paulo: Martins Fontes, 2004.

Recebido em: 30/11/2009

Aceito para publicação em: 09/09/2010 